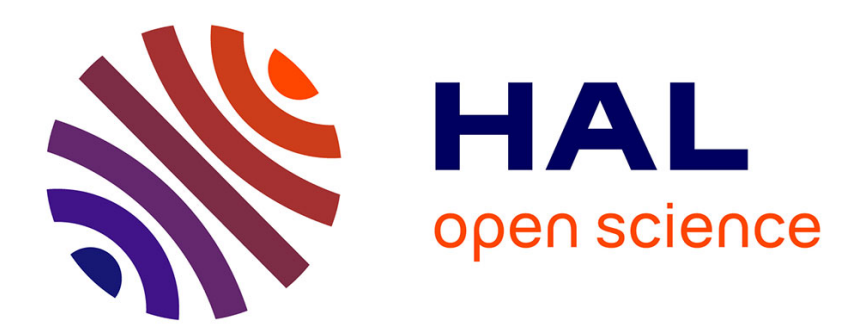

\title{
Growth, deforestation and the efficiency of the REDD mechanism
}

Hélène Ollivier

\section{To cite this version:}

Hélène Ollivier. Growth, deforestation and the efficiency of the REDD mechanism. Journal of Environmental Economics and Management, 2012, 64 (3), pp.312-327. 10.1016/j.jeem.2012.07.007 . hal-00750718

\section{HAL Id: hal-00750718 https://hal.science/hal-00750718}

Submitted on 12 Nov 2012

HAL is a multi-disciplinary open access archive for the deposit and dissemination of scientific research documents, whether they are published or not. The documents may come from teaching and research institutions in France or abroad, or from public or private research centers.
L'archive ouverte pluridisciplinaire HAL, est destinée au dépôt et à la diffusion de documents scientifiques de niveau recherche, publiés ou non, émanant des établissements d'enseignement et de recherche français ou étrangers, des laboratoires publics ou privés. 


\title{
Growth, deforestation and the efficiency of the REDD mechanism
}

\author{
Hélène Ollivier ${ }^{\mathrm{a}}$ \\ ${ }^{a}$ Dept. of Agricultural and Resource Economics, University of California, 207 Giannini \\ Hall, Berkeley, CA 94720-3310. E-mail: helene.ollivier@berkeley.edu.
}

\begin{abstract}
This paper assesses the long term impacts of an international transfer called the Reduced Emissions from Deforestation and Degradation (REDD) mechanism, which aims at preserving tropical forests of the recipient economy. This two-sector economy faces a dilemma between economic growth and deforestation. The rural sector can substitute reproducible capital for agricultural land whereas the manufacturing sector only requires capital. The model shows that the REDD mechanism has a non-monotonic effect on steady state welfares. For low transfer schemes, the agricultural output increases with the transfer even though less land is under cultivation. For high transfer schemes, the increase in the transfer may not offset the decrease in the agricultural output. The open-loop symmetric Nash equilibrium in a dynamic deforestation game predicts that redistributing the transfer among a finite number of producers is less efficient in reducing deforestation than in the social optimum.
\end{abstract}

Keywords: avoided deforestation, growth, aid efficiency JEL: F35, O13, Q56 


\section{Introduction}

Deforestation in the tropics is currently responsible for about a quarter of total world carbon emissions and represents the main source of emissions in some developing countries (Eliasch, 2008). Reducing greenhouse gas emissions in developed countries while developing countries remain excluded from the burden sharing agreement is unlikely to mitigate climate change efficiently. Because curbing deforestation has the potential to offer significant emissions reductions in developing countries, it represents an opportunity to bring developing countries into the international negotiations on climate change. Forest abundant countries would likely agree to participate if they would receive compensation for reducing deforestation that covers the opportunity cost of preserving the land in forest.1. The Reduced Emissions from Deforestation and Degradation (REDD) mechanism offers a transfer that provides the incentive to reduce deforestation in forest-abundant developing countries. This transfer would have an impact on both the environment and economic activities in the recipient country, given that land clearing is often a fuel for growth (Naidoo, 2004).

This paper develops a growth model with land conversion dynamics in a two-sector economy to analyze the role of a transfer mechanism that limits agricultural land expansion. Whereas an unconditional transfer could compensate the forest abundant country for its efforts in preserving forest without creating any distortion, this paper focuses on a transfer that explicitly depends on environmental variables that are used for production. In a small open economy that is initially endowed with a large stock of forest, deforestation occurs due to the higher returns of land converted to agriculture (Hartwick et al., 2001). Aiming at reducing the relative returns from agricultural land compared to forest, the REDD mechanism also creates a price distortion between the two productive factors, agricultural land and capital. This price distortion may be good for the recipient economy if it offsets a previously existing distortion, i.e., if farmers would deforest too much

${ }^{1}$ During the UNFCCC conference of the Parties in Bali in December 2007, the United Nations agreed that climate policies must include a mechanism aiming at reducing tropical deforestation and degradation of forests. A group of fifteen countries called the "Rainforest Coalition Alliance" represents the interests of the deforesting developing countries. This group makes propositions on how to finance this mechanism, and how to estimate and control for deforestation reductions. 
otherwise.

The main result of the paper is that the steady state welfare of the recipient economy first increases with the REDD transfer and then decreases. By assumption, the REDD transfer is a linear function of the remaining stock of forest and of the deforestation rate. The model shows that the higher the transfer, the lower the stock of agricultural land under cultivation at steady state, but also the higher the amount of capital per unit of land. Combining these two effects implies that the steady state agricultural output first increases with the transfer and then decreases. The possibility of increasing the output while less land is under cultivation arises because of the excessive deforestation context. Farmers are lured into deforesting by a short term effect that makes newly cleared land more productive even though this short-term fertility boost disappears quickly. However, there is a feedback effect of deforestation that reduces agricultural production in the long run. In fact, a decrease in the stock of the nearby forest leads to ecosystem disturbances and erosion that reduce agricultural yields (Ehui \& Hertel, 1989). In this context, relatively low REDD transfer schemes induce efficiency gains by adjusting the capital over land ratio in agriculture at steady state. For high transfer schemes, however, the capital over land ratio becomes too high, which leads to a decrease in agricultural output. The steady state welfare depends on the REDD transfer scheme because of both the impact of the transfer on agricultural output and the external revenue it provides. Thus the steady state welfare may decrease for high transfer schemes. This possibility arises even though high transfer schemes raise external revenue as long as this extra revenue does not offset the decrease in agricultural output. The other sector, manufacturing, only requires capital as input, hence its steady state output is unaffected by the REDD transfer.

The model first takes the perspective of a social planner who perfectly controls for land conversion and for its long term feedback effect, while neglecting the greenhouse gas emissions that result from deforestation because its objective is to maximize national welfare. This simplifying assumption departs from the recent literature that focuses on institutional failures, conflicts, and corruption (Barbier et al., 2005; Hotte, 2005; Amacher et al., 2008) to explain the link between deforestation and slow growth patterns.

In the decentralized equilibrium, the model predicts that the REDD mechanism reduces deforestation less efficiently than in the social optimum. The last section of the paper solves the symmetric open-loop Nash equilibrium in a dynamic deforestation game. The REDD transfer is evenly 
redistributed among producers but it depends on the aggregate levels of deforestation and forest stock. Each agricultural producer recognizes that her clearing behavior affects the aggregate levels of deforestation and forest stock. However, each producer neglects the externality that her clearing behavior has on the productivity of other producers' land, as well as on the REDD transfer.

Many economists have emphasized that a transfer conditional on forest preservation needs to provide the right incentives to developing countries to be environmentally efficient. For instance, Stähler (1996) analyzed the perverse incentives given by a variable rate of transfer that leads to a higher level of deforestation, which in turn raises the amount of transfer (due to a scarcity effect); van Soest \& Lensink (2000) advocated the need for a combined mechanism that offers a transfer which increases with the stock of forest and decreases with the deforestation level (using stick-and-carrot tactics). However, focusing on forest stock dynamics, these studies neglect the analysis of broader economic impacts that emerge from input substitution and capital investments. The findings of this paper also relate to the broader literature on aid effectiveness. From the work by Burnside \& Dollar (2000), a large body of empirical literature argues that foreign aid may have detrimental impacts on growth due to inefficient domestic policy, and that conditional aid has more positive impacts when it encourages policies that foster capital investments 2

\section{Background: The REDD mechanism}

An official agreement has recently been achieved on reducing emissions from deforestation and forest degradation (REDD or REDD + ) during the UNFCCC conference of the Parties in Cancun, in December 2010.3 To be

\footnotetext{
${ }^{2}$ Recently, Rajan \& Subramanian (2008); Easterly (2006); Djankov et al. (2008) demonstrate that aid can have detrimental long-term effects on growth, through an institutional channel (weakening institutions and favoring corruption) and through a macroeconomic channel on competitiveness (Dutch disease).

${ }^{3}$ The debate emerged at the conference of the Parties in Bali (2007) and continued at the Copenhagen conference (December, 2009). See www.un-redd.org. REDD includes activities aiming at reducing emissions from deforestation and degradation, whereas REDD + , in addition to REDD, includes enhancing forest carbon stocks through activities such as forest conservation, forest restoration and sustainable forest management (Angelsen et al. 2009 Kanowski et al. 2011).
} 
part of the REDD mechanism, countries must undertake activities according to a phased approach. In the first phase, called "readiness", countries develop national strategies, assess national reference emission levels, and implement a robust and transparent national forest monitoring system. In the second phase, countries implement their national policies aiming at preserving tropical forests. In the third phase, countries can receive performancebased incentive payments, that is, payments for verified emissions reductions. Designing the performance-based incentive scheme is one of the important challenges of the REDD mechanism, but it also offers better prospects for achieving forest preservation than most previous forest policy interventions (Pfaff et al., 2010).

Many drawbacks however limit the expected emission reductions: carbon sequestration in forest is not permanent; there is a risk that deforestation will move toward non participating countries, leading to carbon leakage; and the governance issue is often problematic in tropical developing countries, implying a high risk that the transfer will be diverted to corruption and rent-seeking (Myers, 2007). An important debate rests on the controversial issue on how to evaluate the reference level of deforestation, which can be assessed through past trends in a business-as-usual scenario, political negotiations or econometric modeling (Myers, 2007; Ebeling \& Yasué, 2008; Combes Motel et al., 2009). A reliable source of financing is crucial for the developing countries to decide whether or not they will participate (Eliasch, 2008; Isenberg \& Potvin, 2010). Hence, the large debate on how to evaluate the costs of REDD projects and on how to control and monitor the reduction in deforestation may impede these projects being carrying out.

Because REDD projects are mostly in their infancy, result-based incentive schemes have hardly been implemented, apart from the large bilateral programs of Norway in Brazil, Indonesia, Guyana and Tanzania. As illustrated by the Amazon Fund, donations (USD 1 billion) are linked directly to results, i.e. to emission trends.4 More precisely, payments in a particular year will depend on the difference between emissions from deforestation in the previous year and a reference level, which is the average for the current ten-year calculation period, and which is updated every five years. If

\footnotetext{
${ }^{4}$ See Norwegian initiative on http://www.regjeringen.no/en/dep/md/Selectedtopics/climate/the-government-of-norways-international-/norway-

amazon-fund.html, and more details on the Amazon Fund on http://www.amazonfund.gov.br/FundoAmazonia/fam/site_en/
} 
emissions in a particular year are higher than the reference level, no payment will be made to the Amazon fund in the subsequent year. Hence, this scheme rests on ex-post evaluation of the emissions due to deforestation, and respects national sovereignty because the fund is managed by the Brazilian Development Bank (BNDES). The incentive scheme that performs well for Brazil is however unlikely to suit Guyana, where deforestation hardly occurs despite its large tropical forest. In this context, Norway has offered up to USD 250 millions for preserving the stock of forest in Guyana. Both the deforestation level and the stock of forest can be considered in the incentive scheme, depending on the deforestation patterns of the recipient countries.

This paper is an attempt to assess the impacts of a prospective REDD mechanism on the recipient economies, assuming their deforestation decisions are optimal and abstracting from the risk of international leakage that would relocate land clearing in the neighboring countries. In the absence of consensus on the design of the REDD mechanism, this paper uses a stylized version of Brazil and Guyana incentive schemes.

\section{The analytical framework}

Consider an economy composed of two sectors, agriculture and manufacturing. Each sector has a sector-specific fixed supply of labor and a supply of capital that changes due to investment and depreciation. The agricultural sector also uses land, whose supply depends on the deforestation process. The focus of the paper is on the trade-off between capital accumulation and deforestation, hence the issues of technological change and of knowledge spillovers that generate endogenous growth are neglected. I assume that the country

is a small open economy, so that all prices are given by the international markets.

\subsection{Agricultural expansion and production}

The economy's land endowment is normalized to one unit. Since the economy is initially endowed with a large amount of forested land, the forest stock constitutes a land resource, which is subject to an irreversible conversion by an economic activity, agriculture. Hence, denoting by $F_{t} \geq 0$ the amount of land left in native forests, $L_{t}=1-F_{t}$ represents agricultural land. Initially, the economy has a relatively low endowment $L_{0}$ of agricultural land. Denoting by $d_{t}$ the amount of resource conversion, and using $\dot{x} \equiv d x / d t$ for 
any variable $x$, land use changes over time are determined by

$$
\dot{L}_{t}=d_{t} \text {. }
$$

Assuming that deforestation in the tropics is an irreversible process implies that no reforestation occurs on cleared land. Otherwise, the carbon release due to deforestation would be partially compensated for by the regrowth process.5

Land conversion increases agricultural production, but this effect varies through time. This paper describes two impacts of deforesting on production. The first impact arises from a short-term incentive to deforest because newly cleared land has higher productivity. Empirical evidence in tropical countries show that the clearing and the burning of biomass that usually accompany land conversion release all nutrients at once ${ }^{6}$ After a few years, the newly converted land loses its extra nutrients and productivity falls. The second impact is a long-term stock feedback effect: a reduced forest cover decreases the aggregate productivity of agricultural land. There is also evidence that high deforestation induces a local externality on agricultural production due to ecosystem disturbance. In fact, the tropical acid soils suffer from a fall in protection from the near forest cover, which leads to erosion, and the disturbed local conditions can lead to irregular rainfalls and to a decrease in water supply. This combination of short-term and long-term effects of deforestation on agricultural yields appears in Ehui \& Hertel (1989); Ehui et al. (1990), and is also considered by van Soest \& Lensink (2000); Barbier et al. (2005). It reflects the trade-off between clearing new land and preserving forest at the level of the representative producer.

The agricultural sector output, $y_{a}$, is

$$
y_{a t}=f\left(d_{t}, L_{t}, K_{a t}\right)\left(1-\beta L_{t}\right),
$$

where $f($.$) is a twice differentiable and strictly concave function with respect$ to newly cleared land $d_{t}$, accumulated land $L_{t}$, and rural capital $K_{a t}$, and

\footnotetext{
${ }^{5}$ This paper examines a mechanism aiming at reducing deforestation. I do not consider afforestation and assume that deforestation is irreversible for two main reasons: first, afforestation and forest management projects are already considered in the Clean Development Mechanism of the Kyoto Protocol, whereas deforestation is not; second, accounting for carbon sequestration in the trees requires more information on species and on rotational management (age of the cohorts), as illustrated in Sohngen \& Mendelsohn (2003).

${ }^{6}$ See http://earthobservatory.nasa.gov/Features/Deforestation/
} 
where $1-\beta L$ corresponds to the stock feedback effect of deforestation, with $0<\beta<1$. The parameter $\beta$ is used for performing comparative statics in the rest of the paper. Once a large amount of forest has been cleared, the local externality erodes the incentives to deforest. This feedback effect gives a value to the standing forest, which may avoid its complete depletion. It is an alternative to representing an amenity effect in the utility function. Even the highest feedback effect does not lead to soil infertility or desertification given that production remains positive even when $L_{t}=1$, i.e., when all land are converted to agriculture. To account for the difference in productivity between newly cleared land and land that has been cleared in the past, I assume that newly deforested land $d_{t}$ is more productive than the stock of accumulated agricultural land $L_{t}$ by a constant factor $\nu$. After one period of time, newly converted land loses its extra nutrients and falls into the stock of agricultural land $L_{t}$. This parsimonious representation of land into two classes, one being more productive than the other because it is newly converted, can be compared to the vintage model for capital, where new capital endowing new technology is therefore more productive. I specify $f($. as a Cobb-Douglas function:

$$
f\left(d_{t}, L_{t}, K_{a t}\right)=K_{a t}^{\alpha}\left(L_{t}+\nu d_{t}\right)^{1-\alpha}
$$

where $d_{t}$ and $L_{t}$ are perfect substitutes except that newly deforested land is more productive by a constant factor $\nu>0.7$ The parameter $\nu$ transforms a flow variable into a stock variable by having a time dimension. Both the stocks of land and capital are necessary factors, whereas $d_{t}$ can reach zero without hurting production.

The second sector only requires man-made capital, $K_{n t}$, to produce manufacturing goods. The production function of this sector is

$$
y_{n t}=A K_{n t}^{\eta}, \quad \eta<1
$$

hence it is concave, increasing in the capital input, and satisfies the Inada condition (as the input approaches zero its marginal product tends to infinity). The productivity factor, $A$, is an exogenous constant parameter. The model could be extended as in the endogenous growth literature by assuming

\footnotetext{
${ }^{7}$ If $d_{t}$ and $L_{t}$ were imperfect substitutes in the Cobb-Douglas framework, then deforesting would be necessary for producing $y_{a t}$.
} 
that the productivity parameter is endogenous and evolves over time according to a learning by doing mechanism (Matsuyama, 1992; Torvik, 2001). These learning spillovers however would introduce another source of growth, whereas the focus is on comparing land and capital accumulation dynamics.

Capital is the only intersectorally mobile factor, whereas land is a specific factor to agricultural production. The total stock of capital is $K_{t}=K_{a t}+K_{n t}$, which accumulates depending on the following investment decision:

$$
\dot{K}_{t}=I_{t}-\delta K_{t}
$$

where $I_{t}$ is the amount invested in physical capital at period $t$, evaluated in terms of the agricultural good, which is the numeraire, and $\delta$ is the depreciation rate of capital.

A complete model of development with deforestation would have labor migration as a central component, and would consider labor allocation between the two sectors. Here, I implicitly assume that labor is immobile across sectors and that its supply is fixed in each sector. Rural workers can only clear and cultivate agricultural land whereas urban workers can only produce manufacturing goods. This assumption can be justified by the lack of secured property rights over land (Mendelsohn, 1994; Angelsen, 1999; Hotte, 2001). Urban workers do not migrate because returns are lower in the agricultural sector (due to insecure property rights), whereas rural workers do not migrate because they have a security incentive to stay at home and protect their tenure rights. 8

\subsection{The REDD mechanism}

The developing country's government internalizes the local feedback effect of deforestation on production, while it neglects the global externality that arises from greenhouse gas emissions. Hence, the international community offers a transfer if the government agrees to reduce deforestation at the national scale. This transfer, which is called the REDD mechanism, provides monetary incentives either to preserve the forest stock or to decrease the deforestation level compared to a reference level. A general form of transfer is $S\left(d_{t}, F_{t}\right)$, with $S_{d}<0$ and $S_{F}>0$. Assuming additive separability of the

\footnotetext{
${ }^{8}$ The idea that informal property rights may "tie" households to their property and affect labor market decisions is studied in an urban context in Peru by Field (2007).
} 
transfer function, I use the following linear functional form

$$
S\left(d_{t}, F_{t}\right)=\left\{\begin{array}{cc}
\gamma F_{t}+R\left[d_{b a s}-d_{t}\right] & \text { if } \gamma F_{t}+R d_{b a s} \geq R d_{t} \\
0 & \text { otherwise, }
\end{array}\right.
$$

where $\gamma$ is the rate of transfer per unit of preserved forested land, and $R$ is the price of carbon sequestrated in one hectare of tropical forest (using mean value for biomass yields), and both are assumed to be positive and constant. The first part of the transfer function corresponds to a traditional preservation scheme, where the stock of the resource matters. The second part reflects the current debate on "avoided deforestation": the transfer is proportional to a decrease in deforestation compared to an exogenous baseline level $d_{b a s}$, i.e., proportional to a decrease in carbon emissions.$^{9}$

If the international institution offers a transfer, $S\left(d_{t}, F_{t}\right) \geq 0$, the resulting mechanism is a foreign aid conditional on the environment. Due to its conditionality, the mechanism influences the use and the accumulation decision of one factor (land). The mechanism however also provides a transfer in terms of the agricultural good (numeraire), hence it eases the revenue constraint of consumers and can facilitate investments. The welfare of the developing country must be improved while participating to the mechanism. Political reluctance to join the REDD mechanism for sovereignty reasons are abstracted from.

\subsection{The social planner's problem}

While opening to trade, the small economy expands its agricultural land given the low initial endowment $L_{0}$ relative to world prices. In a centrally planned economy, the government's problem is to maximize the intertemporal utility of the representative agent 10

Let $x_{a}$ denote consumption of the agricultural good and $x_{n}$ consumption of manufacturing goods. Preferences of the representative consumer are given by

$$
U\left(x_{a}, x_{n}\right)=\frac{\epsilon}{\epsilon-1}\left[x_{a}^{\phi} x_{n}^{1-\phi}\right]^{\frac{\epsilon-1}{\epsilon}}
$$

\footnotetext{
${ }^{9}$ The controversial issue on how to evaluate $d_{b a s}$ is not addressed here: I assume that $d_{\text {bas }}$ results from international negotiations. For simplicity reason, I assume that $d_{\text {bas }}$ is constant. Assuming that $d_{\text {bas }}$ was decreasing through time would reduce the magnitude of the impacts.

${ }^{10} \mathrm{I}$ assume that the population size is constant over time. Extension of the model to positive population growth is straightforward. All variables are defined per capita.
} 
where $\epsilon>0$ is a fixed parameter representing the elasticity of inter-temporal substitution, and $0<\phi<1$. Assuming an elasticity of substitution of one between the two goods implies that the shares of revenue devoted to consumption of each good are constant. It simplifies the analysis because the value of consumption of $x_{n}$ is proportional to that of $x_{a}$.

The social planner chooses the consumption and the deforestation patterns that maximize

$$
W=\int_{0}^{\infty} U\left(x_{a t}, x_{n t}\right) e^{-\rho t} d t
$$

where $\rho$ denotes the social rate of time preference, subject to (1) and (5), given $L(0)=L_{0}$ and $K(0)=K_{0}$, with $x_{a t} \geq 0, x_{n t} \geq 0, d_{t} \geq 0$, and $L_{t}=1-F_{t}$, and subject to the budget constraint:

$$
y_{a t}+p y_{n t}+S\left(d_{t}, F_{t}\right) \geq x_{a t}+p x_{n t}+I_{t},
$$

where $p$ is the relative price of manufacturing goods in terms of the numeraire, the agricultural good. The society's total income, coming from production and transfer, must equal or be greater than consumption and investment expenditures (Dixit \& Norman, 1980). If the budget constraint holds with equality (which occurs given the maximization assumption), it necessarily implies balanced trade. The (present-value) Hamiltonian of this problem is

$$
\begin{gathered}
H_{t}=U\left(x_{a t}, x_{n t}\right) e^{-\rho t}+\lambda_{t}\left[y_{a t}+p y_{n t}+S\left(d_{t}, F_{t}\right)-x_{a t}-p x_{n t}-I_{t}\right] \\
+\mu_{t}\left[I_{t}-\delta K_{t}\right]+\chi_{t}\left[K_{t}-K_{a t}-K_{n t}\right]-\psi_{t} d_{t}
\end{gathered}
$$

where $\mu_{t}$ and $\psi_{t}$ denote the co-state variables associated with capital accumulation (5) and with land conversion (1), respectively. $\lambda_{t}$ and $\chi_{t}$ are the Lagrangian multipliers associated with the budget constraint and with the constraint on the stock of capital. $H_{t}$ is defined under the assumption that the agricultural land endowment is within its natural bound, $L_{t} \in[0,1]$.

Applying Pontryagin's maximum principle and assuming an interior solution result in necessary conditions for the optimal allocation of assets in the economy. The first-order conditions with respect to the two consumption goods are

$$
\begin{aligned}
\phi\left(x_{n t} / x_{a t}\right)^{1-\phi}\left[x_{a t}^{\phi} x_{n t}^{1-\phi}\right]^{-1 / \epsilon} e^{-\rho t} & =\lambda_{t} \\
(1-\phi)\left(x_{a t} / x_{n t}\right)^{\phi}\left[x_{a t}^{\phi} x_{n t}^{1-\phi}\right]^{-1 / \epsilon} e^{-\rho t} & =p \lambda_{t} .
\end{aligned}
$$


Using (11) and (12), it follows that at the optimum $x_{a}$ and $x_{n}$ are consumed in fixed proportion for a given level of $p$. Hence, I can represent the consumption optimality conditions in terms of the marginal utility of $x_{a}$ only:

$$
\lambda_{t}=\left(\frac{1-\phi}{\phi p}\right)^{(1-\phi)(\epsilon-1) / \epsilon} x_{a t}^{-1 / \epsilon} e^{-\rho t} .
$$

Condition (13) equalizes the constant-value marginal utility of consumption with the shadow value of income. Because $x_{a}$ and $x_{n}$ are proportional for a given $p$, the rate of growth of the consumer's utility is entirely determined by the rate of growth of $x_{a}$. The first-order conditions that allocate capital across sectors are

$$
\chi_{t}=\lambda_{t} \frac{\partial y_{a t}}{\partial K_{a}}=\lambda_{t} p \frac{\partial y_{n t}}{\partial K_{n}} .
$$

Hence, the marginal returns from capital in agriculture and in the manufacturing sector must be equal.

The Kuhn-Tucker first-order conditions with respect to investment and land accumulation are:

$$
\begin{aligned}
& -\lambda_{t}+\mu_{t} \leq 0, \quad I_{t}\left[-\lambda_{t}+\mu_{t}\right]=0, \quad I_{t} \geq 0 \\
& \lambda_{t}\left[\frac{\partial y_{a t}}{\partial d}+S_{d}\right]-\psi_{t} \leq 0, d\left[\lambda_{t} \frac{\partial y_{a t}}{\partial d}+\lambda_{t} S_{d}-\psi_{t}\right]=0, d \geq 0 .
\end{aligned}
$$

A positive investment in capital implies that the shadow value of the stock of capital is equal to the shadow value of income. Similarly, (16) indicates that the shadow value of additional land conversion, $\psi_{t}$, equals the net benefit from deforesting an additional hectare. It reflects the intertemporal nonarbitrage condition according to which postponing deforestation from one period to another creates no profit. I assume throughout that the nonnegativity constraint on $d$ holds. Deforestation occurs as long as $\psi_{t}>0$, that is $\partial y_{a t} / \partial d>-S_{d}$, to ensure a positive net benefit from deforesting.

The co-state variable dynamics for the assets are

$$
\begin{aligned}
\dot{\mu}_{t} & =-\chi_{t}+\mu_{t} \delta \\
\dot{\psi}_{t} & =\lambda_{t}\left[\frac{\partial y_{a t}}{\partial L}+S_{L}\right] .
\end{aligned}
$$

As in Hartwick et al. (2001), the formulation of the model implies a specific meaning for $\psi_{t}$, because total land area is held constant at unity, hence a small 
decrease in forest is necessarily obtained through an increase in agricultural land. It follows that $\psi(0)$ measures the initial relative desirability of forested land compared to agricultural land. During the deforestation path, one can expect that the relative desirability of forested land will increase. When a large amount of forest has been cleared, however, a high feedback effect can lead to a negative net marginal productivity of the stock of agricultural land. Finally the transversality conditions for this model are given by

$$
\lim _{t \rightarrow \infty} \mu_{t} K_{t}=0, \quad \lim _{t \rightarrow \infty} \psi_{t}\left[1-L_{t}\right]=0 .
$$

Given that (15) implies $\lambda_{t}=\mu_{t}$ when investment is positive, and given (14), differentiating (13) with respect to time and equalizing it to (17) leads to

$$
\dot{x}_{a t} / x_{a t}=\epsilon\left[\frac{\partial y_{a t}}{\partial K_{a}}-(\rho+\delta)\right] .
$$

If the marginal returns from capital are higher than the sum of the discount rate and the depreciation rate, then any inter-temporal elasticity of substitution $\epsilon>0$ is consistent with a growing consumption path (note that the proportionality in consumption of the two final goods implies $\left.\dot{x}_{a t} / x_{a t}=\dot{x}_{n t} / x_{n t}\right)$.

When land conversion occurs $\left(d_{t}>0\right)$, using (16), (18) and (19), as well as the additively separable linear transfer scheme that implies $S_{d F}=S_{d d}=0$, gives

$$
\dot{d}_{t}=-\frac{d_{t}}{\nu}-\frac{L_{t}+\nu d_{t}}{\nu}\left[\frac{\partial y_{a t}}{\partial K_{a}}-\delta-\frac{\dot{K}_{a t}}{K_{a t}}+\frac{1}{\alpha \nu}\left(1-\frac{\beta\left(L_{t}+\alpha \nu d_{t}\right)}{(1-\alpha)\left(1-\beta L_{t}\right)}\right)\right]-\frac{\gamma+R\left(\frac{\partial y_{a t}}{\partial K_{a}}-\delta\right.}{\partial^{2} y_{a t} / \partial d^{2}}(20)
$$

Given that the first two terms of the last expression are negative if $\dot{K}_{a t}<$ $\alpha y_{a t}-\delta K_{a t}$, the deforestation level is likely to be decreasing through time. The third term being positive, it would imply that the transfer influences the patterns of deforestation (through $\gamma$ and $R$ ) by reducing the change in the deforestation level, that is, by smoothing the process of clearing land through time. Notice that if the social discount rate tends toward zero and as the marginal productivity of capital in agriculture converges toward the depreciation rate, the impact of the marginal transfer for avoiding deforestation, $R$, decreases whereas the impact of the marginal transfer for forest preservation, $\gamma$, remains the same.

Below I focus on the steady state of a diversified economy. Because the only mobile factor is capital, whose endowment is not fixed, the small open 
economy is diversified. In fact, the agricultural sector always produces a positive amount of output due to the absence of land use cost. Similarly, the assumption of decreasing returns to scale in the manufacturing sector (implying that there is an implicit factor, labor, which is normalized to one) implies positive profit, and thus this sector also produces a positive amount of output.

\subsection{Steady state analysis}

At steady state, $\dot{x}_{a}=\dot{L}=\dot{d}=\dot{K}=0$. Denote by $x_{a \infty}, K_{a \infty}, K_{n \infty}$ and $L_{\infty}$ the long run levels of food consumption, rural capital, urban capital and agricultural land, respectively. As proved in the appendix $A$, the steady state is a (local) saddle point. A negative exogenous shock in capital, far from increasing the pressure on forest, reduces the incentive to deforest and the economy tends toward the same steady state.

Using (17), (19) and (20), the steady state diversified economy is characterized by the following conditions:

$$
\begin{aligned}
\frac{\partial y_{a}}{\partial K_{a}}=p \frac{\partial y_{n}}{\partial K_{n}} & =\rho+\delta \\
\frac{\partial y_{a}}{\partial L}+\rho \frac{\partial y_{a}}{\partial d} & =S_{F}-\rho S_{d} .
\end{aligned}
$$

Hence, the marginal returns from capital equal the discount rate plus the depreciation rate of capital. Equation (21) thus determines the steady state level of urban capital. Dividing both sides of (22) by $\rho$ implies that the sum of the immediate and discounted future agricultural gains from an additional acre of cleared land equals the immediate and discounted future transfer losses due to this additional deforestation. Notice that $S_{F}-\rho S_{d}$ is a constant denoted by $s \equiv \gamma+\rho R \geq 0$ given (6). The parameters $\gamma$ and $R$ affect separately the transition path, but the steady state depends on these parameters only under the combination $s$. Therefore the parameter $s$ has an important role in the analysis of the REDD impacts on the steady state of the recipient economy. Combining (21) and (22) gives the following implicit equation for the steady state level of agricultural land,

$$
\left(\frac{\alpha(1-\beta L)}{\rho+\delta}\right)^{\frac{\alpha}{1-\alpha}}[\xi-\beta L(1+\xi)]=s,
$$

where $\xi \equiv(1-\alpha)(1+\rho \nu)$. By definition, $L \geq L_{0}$. Denote by $\bar{s}$ the minimum incentive transfer for which the recipient country decides to protect its entire 
stock of forest. Using 23 gives

$$
\bar{s} \equiv\left[\xi-\beta L_{0}(1+\xi)\right]\left[\frac{\alpha\left(1-\beta L_{0}\right)}{\rho+\delta}\right]^{\frac{\alpha}{1-\alpha}} .
$$

Hence,

Lemma 1. The steady state level of agricultural land, $L_{\infty}$, is an interior solution $\left(L_{\infty} \in\left[L_{0}, 1\right]\right)$ determined by (23) for $s \in[0, \bar{s}]$ if $L_{0}, \beta, \alpha$ and $\xi$ satisfy $L_{0}<\xi /[\beta(1+\xi)]$ and

$$
\frac{\xi}{1+\xi}<\beta<\frac{1-\alpha+\xi}{1+\xi}
$$

Proof: cf. the appendix.

Lemma 1 sets restrictions on parameter values so that the steady state level of agricultural land lies between the initial level of agricultural land $L_{0}$ and the entire land endowment. In particular, the initial level of agricultural land needs to be relatively low. H1 compares the feedback effect of deforestation $\beta$ that reduces production with the short-term productivity boost coming from newly deforested land. By definition, $\xi /(1+\xi)$ is increasing in the discounted fertility boost, $\rho \nu$, and in the output elasticity of land, $(1-\alpha)$. The first inequality in $\mathrm{H} 1$ imposes a high feedback effect $\beta$ when the productivity surplus $\nu$ and the discount rate $\rho$ are high, and when the output elasticity of capital $\alpha$ is low. Hence, when the benefits from deforesting are high or when the social planner is impatient, forest preservation takes place if the productivity loss from a disturbed ecosystem is high. $\beta$ is the only factor that represents a damage from deforesting to the developing country. The feedback effect, however, needs to be bounded above, otherwise the productivity loss would cancel the incentive to deforest.

Consider the case where $s=0$ (which implies $\gamma=0$ and $R=0$ due to the additive separability of the transfer function). The developing economy thus receives no external revenue and grows by accumulating land and capital without any constraint on its deforestation path. Given (23), the laissez-faire economy would convert the following amount of land at steady state

$$
L_{\infty}=\frac{\xi}{\beta(1+\xi)}<1
$$

which is decreasing in $\beta$ but increasing in $\rho \nu$. It may be surprising that a short term productivity effect has an impact on the steady state. Because all newly 
deforested land features the same productivity surplus, $\nu$ affects the long run. This discounted fertility boost induces farmers to deforest more than what would be optimal at steady state. The marginal productivity of accumulated

land is negative at steady state: $\partial y_{a} /\left.\partial L\right|_{L=L_{\infty}}=-\frac{\rho \nu}{1+\xi}\left[\frac{\alpha}{(1+\xi)(\rho+\delta)}\right]$, which tends toward zero when $\rho \nu \rightarrow 0$. Because farmers deforest too much, a strong feedback effect of deforestation on production induces the marginal productivity of land to be negative. The social planner however made a tradeoff between the short-term benefits from deforesting (higher productivity) and the long-term feedback effect that was optimal at each period. Observe that if $\rho \rightarrow 0$, an infinitely patient social planner would deforest such that the marginal productivity of land would be nonnegative at steady state. In the context of excessive deforestation in the long run, the REDD mechanism can have a positive impact on the economy by reducing the incentive to deforest at each period.

\section{The impacts of the REDD mechanism}

In the following, I compare the steady states associated with different levels of international transfer (assumed to be constant over time). Comparing steady state welfares is not equivalent to comparing discounted welfares. The impacts of the REDD mechanism on the transition path are not considered. Focusing on steady state welfares, however, makes it possible to compare an environmental achievement (stock of forest) with an economic achievement (domestic production versus external revenue). Denote by $X_{\infty}(s)$ the steady state level of variable $X$ in the economy where the REDD payment scheme $s$ has been introduced.

To find how the REDD payment scheme influences the steady-state economy, I first assess its impacts on the steady state level of agricultural land. For $s \geq \bar{s}$ where $\bar{s}$ is defined by (24), the level of agricultural land would remain at its initial value, hence $L_{\infty}(\bar{s})=L_{0}$. The recipient economy becomes a "forest heaven" and bans deforestation from its territory. In the "forest heaven" economy, growth is limited because only capital can be accumulated, and the steady state level of rural capital is proportional to the small initial level of land. Given that the REDD payment scheme varies on the interval $[0, \bar{s}]$, using 23 and lemma 1 gives

Lemma 2. The introduction of the REDD mechanism reduces the steady state level of agricultural land, which is a decreasing and convex function of 
the transfer scheme, $s$.

Proof: cf. the appendix.

In the long run, the REDD mechanism is environmentally efficient because it reduces deforestation: $L_{\infty}(s) \leq L_{\infty}$, but the marginal impact of the transfer scheme is decreasing. As illustrated in figure 1, the convexity of $L_{\infty}(s)$ with respect to $s$ validates the optimistic view according to which low rates of transfer suffice to reduce sharply deforestation due to low opportunity cost projects (Stern, 2007). The marginal cost of preserving one acre of tropical forest increases while the stock of preserved forest increases.

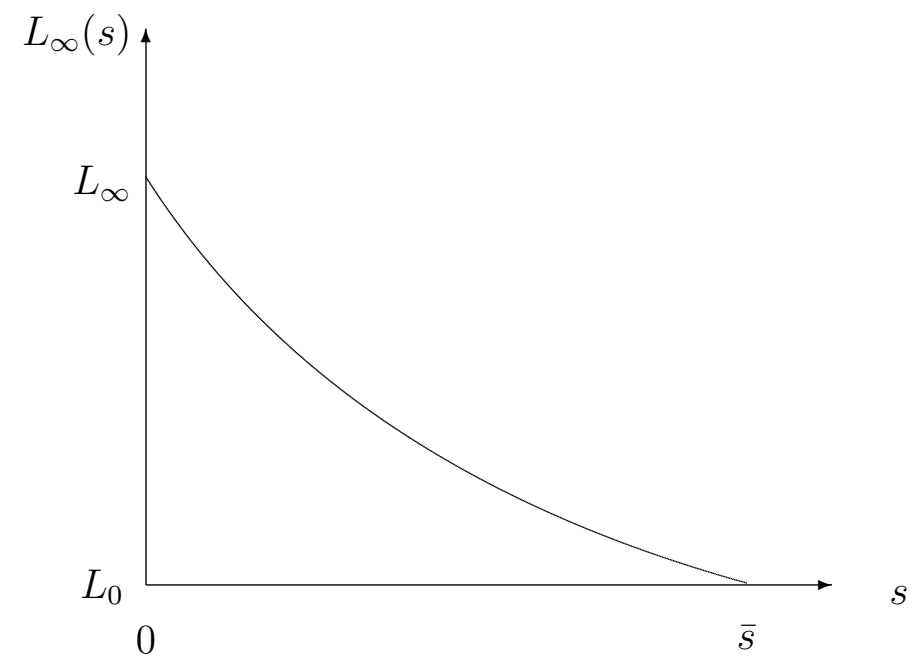

Figure 1: Environmental effect of the REDD mechanism: the higher the transfer scheme $s$ the lower the steady state level of agricultural land $L_{\infty}(s)$.

The impacts of the REDD mechanism on the recipient economy depend on how stringent the environmental constraint is. A higher transfer scheme leads to more external revenue at each period, which has long lasting effects because it facilitates investments. The impacts on the two sectors differ in the long run:

Proposition 1. The REDD mechanism has a technical effect on the rural sector: a higher transfer scheme leads to further agricultural intensification. By contrast, the steady state stock of urban capital is independent of the REDD mechanism. 
Proof: cf. the appendix.

Any increase in the REDD payment scheme substitutes more man-made capital for land in the agricultural sector. This technical effect relies upon the assumption of imperfect factor substitution in the production of good $y_{a}$ (Cobb-Douglas functional form). While agricultural land becomes scarcer when $s$ increases, the representative producer compensates for the "missing land" by intensifying its production. This assumption of imperfect substitution is realistic in the context of agriculture because any agricultural production would require some land.

Proposition 11 also states that the stock of capital in the manufacturing sector is independent of $s$ in the long run ${ }^{11}$ The external revenue coming from the transfer may serve to speed the transition toward the steady state without expanding the long run manufacturing sector. This result rests on the assumption that the manufacturing sector only requires one factor, capital, i.e., there is no migration of labor between the urban and rural sectors. If the relative price $p$ is given by international markets, then $K_{n \infty}$ is fixed in the long run by the golden rule that equates investment with depreciation.

Denote by $s_{A}$ and $s_{C}$ the rates of transfer that maximize the steady state levels of agricultural output and consumption, respectively. As shown in the appendix,

Proposition 2. The economic impacts of the REDD mechanism are

i) For $s<s_{A}$, the steady state levels of agricultural product and rural capital stock are increasing in $s$, whereas they are decreasing in $s$ for $s>s_{A} ;$

ii) Net total income and consumption steady state levels are also concave in $s$ if the change in $s$ is mostly driven by a change in $R$, and thus find a maximum for the transfer scheme $s_{C}$ such that $s_{A}<s_{C} \leq \bar{s}$.

\footnotetext{
${ }^{11}$ If the manufacturing goods were non traded, the relative price $p_{t}$ would reflect the real exchange rate of the economy and would vary through time. Given the functional form of the utility function (7), the budget shares for consuming both goods remain proportional. Hence, if a high REDD scheme increases (reduces) the relative price of the non-traded good, the steady state stock of urban capital would decrease (increase). As in the Dutch disease literature (Corden \& Neary, 1982), a real appreciation would lead to a decline in the long term urban sector.
} 
Proof: cf. the appendix.

Point $i /$ states that for relatively low transfer schemes, the conditional transfer induces both a decrease in the steady state level of agricultural land and a rise in the agricultural product. The agricultural sector benefits from the transfer because it reduces its land intensity in a context where the marginal productivity of land is negative at steady state. This is illustrated by $(22)$, which can be rewritten as $\partial y_{a} / \partial L=s-\rho \partial y_{a} / \partial d$, which is negative for low levels of transfer scheme. The social planner trading off the short term benefits and the long term feedback effect of deforestation notwithstanding, it is the short-term fertility boost from newly cleared land that induces farmers to deforest too much compared to the long-run productivity of the land. By reducing the incentive to deforest at each period, the REDD mechanism improves the long term efficiency of the agricultural sector. The steady state level of rural capital increases with $s$ when $s<s_{A}$. For high transfer schemes, however, the environmental constraint implies that the agricultural sector shrinks. The rural sector faces the limits of factor substitution. Despite the technical effect shown above, decreasing marginal returns imply that a higher steady state level of rural capital is not sufficient to maintain production. The price distortion introduced by the REDD mechanism raises the ratio of capital over land too much, which leads to efficiency losses.

Point $i$ / illustrates the impacts of the REDD mechanism on the steady state welfare. The economy relies on three sources of income: the manufacturing output, the agricultural output and the international transfer. The manufacturing output is independent of the transfer scheme at steady state. The two other sources of income, which form the agriculture-related income, depend on the transfer either directly or indirectly through the amounts of agricultural land and rural capital. The steady state welfare that only depends on consumption levels is thus a function of the agriculture-related income. Given the definition of $s$ as $\gamma+\rho R$, the agriculture-related income at steady state is

$$
W_{a \infty}(s) \equiv y_{a \infty}(s)-\delta K_{a \infty}(s)+\gamma\left[1-L_{\infty}(s)\right]+(s-\gamma) d_{b a s} / \rho .
$$

While the external revenue from the transfer is increasing in $s$, the net revenue from the agricultural sector is increasing in $s$ when $s \leq s_{A}$ and decreasing in $s$ when $s>s_{A}$. This result leads to the non-monotonicity of the steady state welfare in $s$ if the agriculture-related income is concave and finds a maximum for $s_{C} \in\left[s_{A}, \bar{s}\right]$. This possibility arises when the change in $s$ is mostly driven 
by a change in the compensation offered for a reduction in the deforestation rate, $R$. In this context, the impact of a variation in $s$ on the agricultural output outweighs its impact on the transfer. Hence, high transfer schemes decrease the steady state welfare. Otherwise, the steady state welfare finds a maximum for $s_{C}=\bar{s}$. Figure 2 illustrates the case where the steady state welfare decreases with $s$ for high transfer schemes.

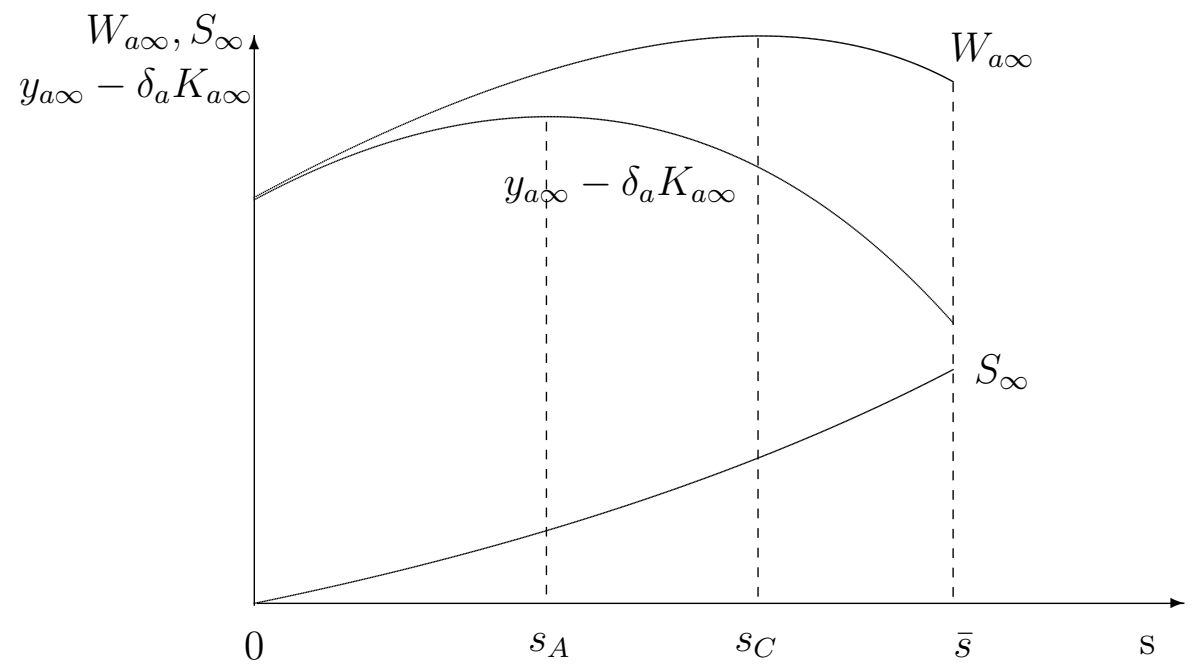

Figure 2: Impacts of the REDD mechanism on the agriculture-related income, i.e., on agricultural returns and on the conditional transfer.

Reinterpreting the model as a Ricardo-Viner model where agriculture uses land as a specific factor while manufacturing uses a hidden fixed factor, labor, offers another explanation for the steady state stock of urban capital being unaffected by the REDD mechanism while the stocks of rural capital and land vary. Because capital is the only mobile factor, the relative size of the two industries depends on the capital market clearing condition. Figure 3 illustrates the equilibrium where the marginal returns from capital are equal across sectors and more precisely equal to $\rho+\delta$ at steady state. Simplified notations $p y_{n}^{\prime}$ and $\left.y_{a}^{\prime}\right|_{\bar{K}, \bar{L}}$ reflect the fact that only the marginal returns from rural capital depend on the aggregate stocks of land and capital. Suppose the transfer scheme $s$ increases. Lemma 2 states that the stock of agricultural land decreases, which affects the marginal returns from rural capital. For 
a low transfer scheme $s<s_{A}$, the decrease in agricultural land from $\bar{L}$ to $\bar{L}^{\prime}$ raises the marginal productivity of capital in agriculture (cf. proposition 2). This possibility arises because of the context of excessive deforestation. Figure $3 a$ ) illustrates the inner shift of the marginal returns from rural capital from $\left.y_{a}^{\prime}\right|_{\bar{K}, \bar{L}}$ (bold curve) to $\left.y_{a}^{\prime}\right|_{\bar{K}, \bar{L}^{\prime}}$. Holding the capital stock constant, the REDD mechanism would reduce the amount of capital used by manufacturing and increase the marginal returns from capital. However, the steady state condition (21) requires that the marginal returns from capital equal $\rho+\delta$. Hence, increasing the aggregate stock of capital from $\bar{K}$ to $\bar{K}^{\prime}$ will reduce the marginal returns from capital by shifting the curve $\left.y_{a}^{\prime}\right|_{\bar{K}, \bar{L}^{\prime}}$ to the right

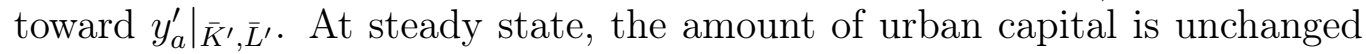
whereas agriculture has absorbed any additional stock of capital. Figure 33 ) illustrates the case with high transfer schemes $\left(s>s_{A}\right)$ where an increase in $s$ decreases the marginal productivity of rural capital, which would reduce the marginal returns from capital except for the capital stock reduction.

The long term impacts of the REDD mechanism on the recipient economy are positive for low transfer schemes because it reduces excessive deforestation. With high transfer schemes, however, it is optimal for the social planner to choose a deforestation path at which the steady state welfare is smaller than with lower transfer schemes.

\section{Decentralized solution using the open-loop equilibrium in a dy- namic deforestation game}

Whereas the REDD impacts in the social planner's case rely on perfect monitoring of deforestation, redistributing REDD transfers to farmers might lead to different outcomes. In the decentralized equilibrium, the representative household consumes and invests in capital while she receives revenue from lending her capital to producers who are producing either agricultural or manufacturing goods. All economic agents are infinitely-lived, and the household's preferences are given by (7).

First, consider the representative household's decisions. Denote by $r$ the rate of returns from capital. The problem of the representative household is to maximize the discounted flow of utility from consumption, subject to the revenue constraint: $I_{t}=r_{t} K_{t}-x_{a t}-p x_{n t}$, given (5) and $K(0)=K_{0}$. The household determines the optimal levels of consumption and investment in capital, given that capital depreciates at rate $\delta$, and that she receives a unit payment $r_{t}$ for lending her capital. The solution must respect conditions that 
a) For $s<s_{A}$

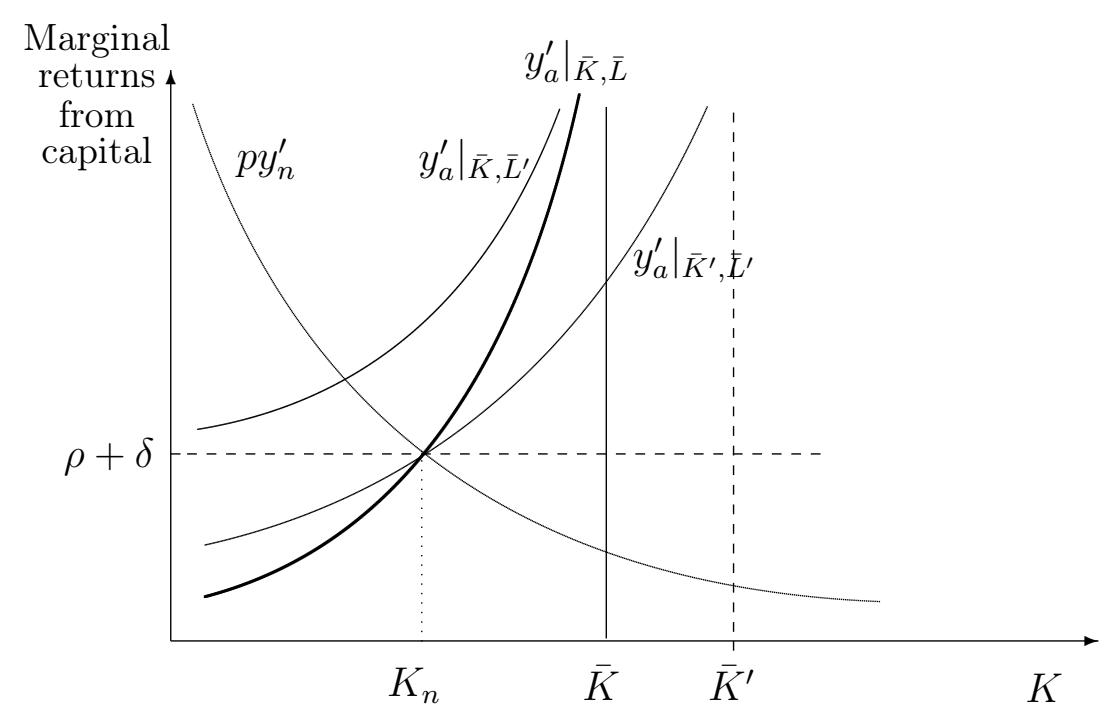

b) For $s>s_{A}$

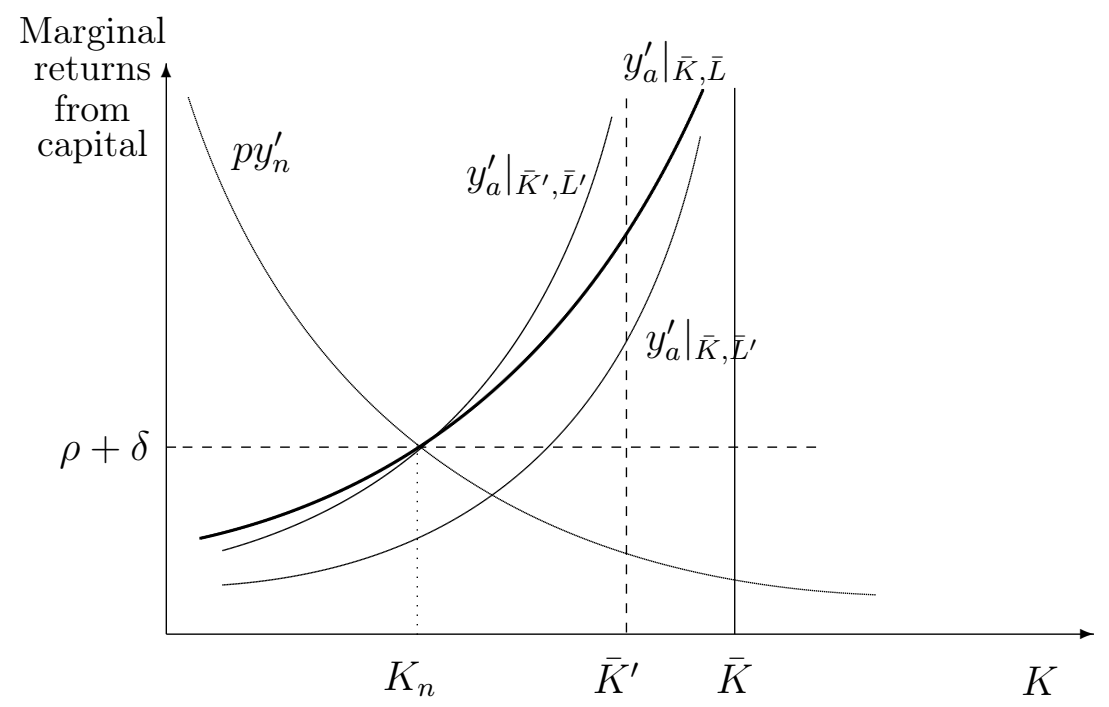

Figure 3: Marginal returns from capital in both sectors and variation in the stocks of land and capital.

are similar to 13$),(15)$, and 17 , except that $r_{t}$ substitutes for the marginal 
returns from capital. It can be easily shown that solving the representative household's program leads to the following condition:

$$
r_{t}-\delta=\rho+\frac{1}{\epsilon} \frac{\dot{x}_{a t}}{x_{a t}}
$$

Second, the representative urban producer maximizes her profit under perfect competition by choosing the level of capital use, which gives the condition: $r_{t}=p \partial y_{n t} / \partial K_{n}$ at each period. Combining this condition with (27) implies that the trade-off between consumption and investment while only taking into account the manufacturing sector is similar to the social planner's trade-off.

Third, each agricultural producer determines both the level of rural capital and the amount of land to use, hence the decision to deforest lies in her hands. Assume that, once an acre has been deforested, the farmer is the owner of the land. There is evidence that land clearing often gives the settler tenure rights (Angelsen, 1999). The REDD transfer (6) is redistributed to farmers to influence their decision to deforest. Because it depends on the aggregate levels of deforestation, the mechanism is effective only if farmers recognize that their clearing behaviors affect aggregate levels. If farmers believed that aggregate deforestation levels were fixed, they would view the transfer as a lump sum transfer, and the mechanism would not impact their decisions about deforesting. Deforestation is thus similar to a nonpoint source pollution problem (Karp, 2005).

Assume a finite number of rural producers, $n$. Each farmer considers her clearing behavior to have a small impact on the stock of forest, taking as given the other farmers' stock of land and deforestation level. Each of the $n$ farmers' individual deforestation level is $d_{i}$ while her stock of land is $\ell_{i}$. Assuming that the regulator has imperfect information on the individual levels of deforestation, it simply redistributes an even share $(1 / n)$ of the transfer to each farmer. I thus solve the open-loop Nash equilibrium to determine the deforestation patterns. In this setting, the open-loop equilibrium is time consistent, but it is not subgame perfect. Given the complexities of the model, using the open-loop equilibrium makes it possible to raise some interesting points in a simple setting.

The representative farmer increases her stock of agricultural land $\ell_{i t}$ by clearing new land according to

$$
\dot{\ell}_{i t}=d_{i t}
$$


Her production function is $y_{a i}=f\left(d_{i}, \ell_{i}, k_{a i}\right)(1-\beta L)$, where $f\left(d_{i}, \ell_{i}, k_{a i}\right)=$ $k_{a i}^{\alpha}\left(\ell_{i}+\nu d_{i}\right)^{1-\alpha}$ and $k_{a i}$ is the individual use of rural capital, and where $(1-\beta L)$ represents the feedback effect of aggregate deforestation on production. Each farmer chooses a trajectory $\left\{d_{i t}, k_{\text {ait }}\right\}_{0}^{\infty}$ to maximize the present discounted value of profits that include the redistributed transfer, that is, $\int_{0}^{\infty}\left[f\left(d_{i t}, \ell_{i t}, k_{a i t}\right)(1-\beta L)-r_{t} k_{a i t}+S\left(d_{t}, L_{t}\right) / n\right] e^{-\int_{0}^{t} r_{s} d s} d t$, subject to (28), $d_{t}=d_{i t}+(n-1) d_{j t}, L_{t}=\ell_{i t}+(n-1) \ell_{j t}$, and $K_{a t}=k_{a i t}+(n-1) k_{a j t}$ with $j \neq i$, and $d_{i t} \geq 0$. In an open-loop equilibrium, each farmer takes as given the input accumulation trajectory of the other farmers $\left\{d_{j t}, \ell_{j t}, k_{a j t}\right\}_{0}^{\infty}$. Capital allocates optimally to rural production at each period according to

$$
r_{t}=\partial y_{a i} / \partial k_{a i}
$$

Hence, the representative household lends her capital to both sectors if the marginal returns from capital are equal across sectors. Denoting by $\psi_{i t}$ the co-state variable associated with land conversion, the necessary conditions for a symmetric open-loop interior Nash equilibrium are

$$
\begin{aligned}
\psi_{i t} & =\left[\partial y_{a i} / \partial d_{i}-R / n\right] e^{-\int_{0}^{t} r_{s} d s}, \\
\dot{\psi}_{i t} & =\left[\frac{\partial f(.)}{\partial \ell_{i}}(1-\beta L)-\beta f(.)-\gamma / n\right] e^{-\int_{0}^{t} r_{s} d s},
\end{aligned}
$$

and the transversality condition is $\lim _{t \rightarrow \infty} \psi_{i t}\left[1-\ell_{i t}-(n-1) \ell_{j t}\right]=0$. Equalizing the time derivative of (30) with (31) determines the steady state individual stock of land as a function of the aggregate stock of land

$$
\frac{\partial f(.)}{\partial \ell_{i}}(1-\beta L)-\beta f(.)-r \frac{\partial f(.)}{\partial d_{i}}(1-\beta L)=\frac{\gamma+r R}{n}
$$

which differs from (22) in three ways: first, $r$ replaces the social planner's discount rate $\rho$; second, the representative farmer only takes into account the feedback effect from her decision to deforest on her production, neglecting the externality on other producers; and third, the marginal transfer loss from deforesting is divided by the number of farmers $n$.

At the symmetric open-loop equilibrium, all farmers adopt the same trajectory, hence $L_{t}=n \ell_{i t}$ for all $t$. Combining (29) and (32) implies

$$
\left(\frac{\alpha(1-\beta L)}{r}\right)^{\frac{\alpha}{1-\alpha}}\left[\xi_{a}-\beta L\left(\frac{1}{n}+\xi_{a}\right)\right]=\frac{\gamma+r R}{n},
$$


where $\xi_{a} \equiv(1+\nu r)(1-\alpha)$. Using 27$)$ implies that $r=\rho+\delta>\rho$ at steady state. Therefore, $\xi_{a}>\xi$. In the absence of transfer $(\gamma=0, R=0)$, farmers will deforest until the following aggregate level of agricultural land is $\tilde{L}_{\infty}=\xi_{a} /\left[\beta\left(1 / n+\xi_{a}\right)\right]$ at steady state. Because the steady state aggregate stock of agricultural land is increasing in $\xi_{a}$, even if there was only one farmer $(n=1)$ more deforestation would occur in the decentralized equilibrium than in the social optimum in the laissez-faire economy. As the number of farmers increases, the aggregate level of agricultural land increases. No forest remains at steady state if $n \geq \beta /\left[\xi_{a}(1-\beta)\right]$.

For a given positive transfer scheme $(\gamma \geq 0, R \geq 0)$, the environmental impacts of the REDD mechanism in the decentralized equilibrium differ from the impacts in the social optimum. First, farmers' decision to deforest depends on different opportunity costs, which are represented by the right hand side of (33) and of (23). Because the discount rate differs and because the transfer is divided among $n$ producers in the decentralized equilibrium, the opportunity cost of deforesting $(\gamma+r R) / n$ is lower than $s=\gamma+\rho R$ if and only if $(n-1) s>R \delta$, which holds for $n>1$ and $\delta<(n-1) \rho$. The transfer being redistributed evenly across farmers, a common property problem diminishes its impact on the aggregate level of deforestation when the number of farmers is large. The REDD mechanism hardly reduces deforestation when the number of farmers tends toward infinity. If however the number of farmers is limited, the higher discount rate of the representative producer may mitigate this effect by magnifying the rate of transfer for avoiding deforestation, $R$. Second, the monetary incentive to achieve the same reduction in aggregate deforestation is higher in the decentralized equilibrium compared to the social optimum. This result compares the left hand side of (33) and of (23), and the details are in the appendix. The following proposition summarizes the results for the environmental impact:

Proposition 3. In the open-loop symmetric equilibrium where farmers receive an even share of the REDD transfer, the transfer scheme $(\gamma, R)$ reduces deforestation less efficiently than in the social optimum.

Proof: see the appendix.

The environmental impact of the REDD mechanism in the decentralized equilibrium is lower than in the social optimum, and this discrepancy widens as the number of farmers increases. This result implies that the impacts of the REDD mechanism on the steady state agriculture-related income in the decentralized equilibrium are also lower, but qualitatively similar. 
The open-loop equilibrium assumes that farmers make binding decisions about their future deforestation levels at the initial period. If any farmer were to deviate from equilibrium, the remaining plan of future deforestation of all farmers would no longer constitute an equilibrium. Hence, the openloop equilibrium is not subgame perfect. This shortcoming is well known. By contrast, a Markov Perfect equilibrium, in which all farmers condition their actions on the state variable (here, the stock of agricultural land), is subgame perfect, but the equilibrium is not unique. Assuming that each farmer's decision to deforest depends negatively on the aggregate stock of agricultural land, farmers' deforestation levels become strategic substitutes. If farmer $i$ expects other farmers to reduce their deforestation levels when the aggregate stock of land increases, she has an incentive to over-deforest. The Markov Perfect equilibrium thus might lead to even less reduction in deforestation than the open-loop equilibrium.

\section{Concluding remarks}

The REDD mechanism plays the role of a conditional aid for a forestabundant small open developing economy. This transfer has a non-monotonic effect on the steady state welfare of the economy. The non-linear effect of the conditional aid on the agricultural product at steady state reflects a type of "Aid Laffer curve" (Lensink \& White, 2001). Using a growth model that allows for substitution between land and capital, I find that the REDD mechanism has two impacts on the economy. First, it deters deforestation and reduces the use of land in agriculture, which increases agricultural productivity for relatively low transfer schemes and decreases it for high transfer schemes. Second, it provides an external revenue that can be used for consumption or for capital investments. When the increase in the external revenue does not compensate for the decrease in agricultural output, the REDD mechanism induces the social planner to choose a deforestation path at which the steady state welfare is smaller than with lower transfer schemes. In the literature on aid effectiveness, this detrimental impact often passes through an institutional channel (by favoring corruption) or through a diminishing-competitiveness channel. Here, in the absence of corrupted behavior and using a two-sector growth model, it is only generated by a higher opportunity cost of reducing deforestation. Should the REDD mechanism considered in this paper become a formal international agreement, policy makers should be aware that setting a transfer that is too high could result in 
lower long run welfare. This result however needs to be interpreted carefully because it stems from a model with no possibility for growth in the long run. Introducing technological progress, in particular if the rate of progress depends on capital accumulation, may alter this result.

Given the absence of consensus on the design of an efficient incentivebased transfer scheme that would reduce deforestation, the model illustrates several important points. First, the incentive must be given at the national level. We find that the REDD mechanism succeeds in raising the costs of deforestation at the national level. However, implementing the mechanism at the decentralized level requires strong monitoring and control from the national government when individual farmers neglect the local externality of deforesting on others' production. Second, the opportunity cost of preserving one acre of forest depends on the amount of land that remains forested in the long run. Different transfer schemes lead to different forest stocks in the long run. The benefits of land clearing are higher when the agricultural land endowment is relatively small, given world prices. Third, agricultural land is an asset that can be accumulated, and both capital and land endowments can increase in a growing economy. This dynamic aspect must be considered when evaluating the opportunity costs of REDD projects.

\section{Acknowledgements}

I would like to thank, without implicating, Jean-Marc Bourgeon, Larry Karp, Gilles Lafforgue, Geoffrey Barrows, two anonymous referees and the editor of the SURED special issue. I acknowledge receiving a S.V. CiriacyWantrup Postdoctoral Fellowship at the department of Agricultural and Resource Economics, University of California, Berkeley. I am also grateful for financing from the Chaire du Développement Durable of the Ecole Polytechnique, France.

\section{References}

Amacher, G., Koskela, E., \& Ollikainen, M. (2008). Deforestation and land use under insecure property rights. Environment and Development Economics, (pp. $1-23)$.

Angelsen, A. (1999). Agricultural expansion and deforestation: modelling the impact of population, market forces and property rights. Journal of development economics, $58,185-218$. 
Angelsen, A., Brown, Loisel, Peskett, Streck, \& Zarin (2009). Reducing Emissions from Deforestation and Forest Degradation (REDD): An Options Assessment Report. Meridian Institute.

Barbier, E. B., Damania, R., \& Léonard, D. (2005). Corruption, trade and resource conversion. Journal of Environmental Economics and Management, 50, 276-299.

Burnside, C. \& Dollar, D. (2000). Aid, policies, and growth. American Economic Review, (pp. 847-868).

Combes Motel, P., Pirard, R., \& Combes, J. (2009). A methodology to estimate impacts of domestic policies on deforestation: Compensated Successful Efforts for avoided deforestation (REDD). Ecological Economics, 68(3), 680-691.

Corden, W. M. \& Neary, J. P. (1982). Booming sector and de-industrialisation in a small open economy. The Economic Journal, 92(368), pp. 825-848.

Dixit, A. \& Norman, V. (1980). Theory of international trade: A dual, general equilibrium approach. Cambridge University Press.

Djankov, S., Montalvo, J., \& Reynal-Querol, M. (2008). The curse of aid. Journal of Economic Growth, 13(3), 169-194.

Easterly, W. (2006). Reliving the 1950s: the big push, poverty traps, and takeoffs in economic development. Journal of Economic Growth, 11(4), 289-318.

Ebeling, J. \& Yasué, M. (2008). Generating carbon finance through avoided deforestation and its potential to create climatic, conservation and human development benefits. Philosophical Transactions of the Royal Society B: Biological Sciences, 363(1498), 1917-1924.

Ehui, S. \& Hertel, T. (1989). Deforestation and Agricultural Productivity in the Cote d'Ivoire. American Journal of Agricultural Economics, 71(3), 703-711.

Ehui, S., Hertel, T., \& Preckel, P. (1990). Forest resource depletion, soil dynamics, and agricultural productivity in the tropics. Journal of Environmental Economics and Management, 18(2), 136-154.

Eliasch, J. (2008). Climate change: financing global forests. Earthscan/James \& James.

Field, E. (2007). Entitled to Work: Urban Property Rights and Labor Supply in Peru*. Quarterly Journal of Economics, 122(4), 1561-1602. 
Hartwick, J., Van Long, N., \& Tian, H. (2001). Deforestation and Development in a Small Open Economy. Journal of Environmental Economics and Management, 41(3), 235-251.

Hotte, L. (2001). Conflicts over property rights and natural-resource exploitation at the frontier. Journal of Development Economics, 66(1), 1 - 21.

Hotte, L. (2005). Natural-resource exploitation with costly enforcement of property rights. Oxford Economic Papers, 57(3), 497-521.

Isenberg, J. \& Potvin, C. (2010). Financing REDD in developing countries: a supply and demand analysis. Climate Policy, 10(2), 216-231.

Kanowski, P. J., McDermott, C. L., \& Cashore, B. W. (2011). Implementing redd+: lessons from analysis of forest governance. Environmental Science and Policy, 14(2), 111 - 117.

Karp, L. (2005). Nonpoint source pollution taxes and excessive tax burden. Environmental and Resource Economics, 31, 229-251.

Lensink, R. \& White, H. (2001). Are there negative returns to aid? Journal of development Studies, 37(6), 42-65.

Matsuyama, K. (1992). Agricultural productivity, comparative advantage, and economic growth. Journal of Economic Theory, 58(2), 317 - 334.

Mendelsohn, R. (1994). Property rights and tropical deforestation. Oxford Economic Papers, 46, 750-756.

Myers, E. C. (2007). Policies to Reduce Emissions from Deforestation and Degradation (REDD) in Tropical Forests: An Examination of the Issues Facing the Incorporation of REDD into Market-Based Climate Policies. Resource for the Future WP.

Naidoo, R. (2004). Economic growth and liquidation of natural capital: the case of forest clearance. Land Economics, 80(2), 194.

Pfaff, A., Sills, E., Amacher, G., Coren, M., Lawlor, K., \& Streck, C. (2010). Policy impacts on deforestation: lessons learned from past experiences to inform new initiatives. Nicholas Institute for Environmental Policy Solutions, Duke University, NI R 10-02.

Rajan, R. \& Subramanian, A. (2008). Aid and growth: what does the cross-country evidence really show? The Review of Economics and Statistics, 90(4), 643-665. 
Sohngen, B. \& Mendelsohn, R. (2003). An optimal control model of forest carbon sequestration. American Journal of Agricultural Economics, 85(2), 448-457.

Stähler, F. (1996). On International compensations for environmental stocks. Environmental and Resource Economics, 8(1), 1-13.

Stern, N. (2007). The economics of climate change: the Stern review. Cambridge University Press.

Torvik, R. (2001). Learning by doing and the dutch disease. European Economic Review, 45(2), $285-306$.

van Soest, D. \& Lensink, R. (2000). Foreign Transfers and Tropical Deforestation: What Terms of Conditionality? American Journal of Agricultural Economics, 82(2), 389-399. 


\section{Appendix}

\section{Appendix A. Local stability of the steady state}

Since more cleared land would lead to another steady state, consider $d=0$ and $L$ fixed. Using 14$)$ implies $K_{n}=\left[\left(\partial y_{a} / \partial K_{a}\right) /(p A \eta)\right]^{\frac{1}{\eta-1}}$ and

$$
\dot{K}_{n}=\frac{1}{p(\eta-1) \eta A} K_{n}^{2-\eta} \frac{\partial^{2} y_{a}}{\partial K_{a}^{2}} \dot{K}_{a}
$$

By definition, $K=K_{a}+K_{n}$, hence $\dot{K}=\dot{K}_{a}+\dot{K}_{n}$. Given the expression of $K_{n}$ in terms of $K_{a}, K_{a}$ can thus be expressed as a function of $K$. Using (5), (9) and (19) gives the following dynamic equations:

$$
\begin{aligned}
& \dot{K}=y_{a}+p A K_{n}^{\eta}+S(1-L, 0)-x_{a} / \phi-\delta K \\
& \dot{x}_{a}=\epsilon x_{a}\left[\partial y_{a} / \partial K_{a}-(\rho+\delta)\right] .
\end{aligned}
$$

At the diversified steady state equilibrium,

$$
\begin{aligned}
\delta K & =K_{a}^{\alpha} L^{1-\alpha}(1-\beta L)+p A[(\delta+\rho) /(p A \eta)]^{\frac{\eta}{\eta-1}}+\gamma(1-L)+R d_{b a s}-x_{a} / \phi \\
\delta+\rho & =\alpha\left[L / K_{a}\right]^{1-\alpha}(1-\beta L) .
\end{aligned}
$$

Hence, using a first order Taylor development,

$$
\left[\begin{array}{c}
\dot{K} \\
\dot{x}_{a}
\end{array}\right]=\left[\begin{array}{cc}
\chi_{K} & \chi_{K x} \\
\chi_{x K} & 0
\end{array}\right]\left[\begin{array}{c}
K-K_{\infty} \\
x_{a}-x_{a \infty}
\end{array}\right]
$$

where $\chi_{K x}=-1 / \phi<0$ and

$$
\chi_{x K}=-\epsilon(1-\alpha)(\delta+\rho)\left(x_{a} / K_{a}\right)\left[1+\frac{(1-\alpha) K_{n}}{(1-\eta) K_{a}}\right]^{-1}<0 .
$$

Hence, the Jacobian matrix is characterized by the determinant $\operatorname{det} J_{E}=$ $-\chi_{x K} \chi_{K x}<0$. To establish that the steady state is locally a saddle point, the two roots of the Jacobian matrix must have opposite signs, which always holds because $\operatorname{det} J_{E}<0$.

Consider an exogenous shock in capital, which reduces $K_{\infty}$ by $\Psi$. The classical trade-off between consumption and investment implies a temporary decrease in consumption, which should be sufficient to reinvest in capital 
and to compensate for the impact of the shock. However, the shock in capital may increase the pressure to deforest, which would modify instantaneously the steady state. Because the decrease in capital implies a decrease in the marginal productivity of deforesting, using (16) gives at steady state $\lambda_{\infty}\left[\partial y_{a \infty} / \partial d+S_{d}\right]<\psi_{\infty}$, which implies that $\partial H / \partial d<0$ and $d=0$. Hence, a shock in capital results in a land surplus compared to the capital level in agriculture, which reduces the marginal productivity of deforesting. Thus the economy tends toward the same steady state.

\section{Appendix B. Proof of Lemma 1}

23. can be expressed as $h(L)-s=0$, with

$$
h(L)=[\alpha(1-\beta L) /(\rho+\delta)]^{\frac{\alpha}{1-\alpha}}[\xi-\beta L(1+\xi)] .
$$

We have

$$
h^{\prime}(L)=-\frac{\beta}{1-\alpha}\left[\frac{\alpha(1-\beta L)}{\rho+\delta}\right]^{\frac{\alpha}{1-\alpha}}\left[1+\xi-\frac{\alpha}{1-\beta L}\right]
$$

whose sign depends on the last bracketed term, which is positive if and only if $L<(1-\alpha+\xi) /[\beta(1+\xi)]$. Since $L \in[0,1]$, a sufficient condition for $h^{\prime}(L)<0$ is that $\beta<1-\alpha /(1+\xi)$. Furthermore, (23) has a unique solution when $s=0$ if $h(0)$ and $h(1)$ have opposite signs. We have $h(0)=\xi[\alpha /(\rho+\delta)]^{\alpha /(1-\alpha)}>0$ and $h(1)<0$ iff $\beta>\xi /(1+\xi)$. More precisely, we must have $h\left(L_{0}\right)>0$ which holds iff $L_{0}<\xi /[\beta(1+\xi)]$. For $s>0$, we have an interior solution iff $h(0) \geq s$, which imposes an upper bound on $s$. Using (24), this upper bound corresponds to $\bar{s}$. Hence, $\xi /(1+\xi)<\beta<1-\alpha /(1+\xi)$ and $L_{0}<\xi /[\beta(1+\xi)]$ are sufficient for finding a unique solution to $(23)$ for $s \in[0, \bar{s}]$.

\section{Appendix C. Proof of lemma 2}

$L_{\infty}(s)$ is a function satisfying $L_{\infty}(0)=L_{\infty}$ and $L_{\infty}(\bar{s})=L_{0}$, which is determined by $h\left(L_{\infty}(s)\right)=s \geq 0$, using (B.1). Using the implicit function theorem gives

$$
L_{\infty}^{\prime}(s)=1 / h^{\prime}\left(L_{\infty}(s)\right)
$$

Given lemma 1, $h($.$) is a strictly decreasing function. Hence, L_{\infty}(s)$ is a decreasing function of $s$, and finds a maximum in $L_{\infty}$. Using $L_{\infty}^{\prime \prime}(s)=$ 
$-h^{\prime \prime}\left(L_{\infty}(s)\right)\left[L_{\infty}^{\prime}(s)\right]^{2} / h^{\prime}\left(L_{\infty}(s)\right)$ and

$$
h^{\prime \prime}(L)=-\frac{\beta \alpha h^{\prime}(L)}{(1-\alpha)(1-\beta L)}+\frac{\beta^{2}}{(1-\alpha)(1-\beta L)^{2}}\left[\frac{\alpha(1-\beta L)}{\rho+\delta}\right]^{\frac{\alpha}{1-\alpha}}>0,
$$

hence $L_{\infty}(s)$ is a convex function of $s$.

\section{Appendix D. Proof of Proposition 1}

Given (21), the rural capital over land ratio at steady state is

$$
K_{a \infty}(s) / L_{\infty}(s)=\left[\alpha\left(1-\beta L_{\infty}(s)\right) /(\rho+\delta)\right]^{1 /(1-\alpha)},
$$

which is unambiguously decreasing in $L_{\infty}(s)$. Using lemma $2, K_{a \infty}(s) / L_{\infty}(s)$ is thus increasing in $s$. Using 21 also gives $K_{n \infty}=[p \eta A /(\rho+\delta)]^{\frac{1}{1-\eta}}$, which is independent of $s$.

\section{Appendix E. Proof of Proposition 2}

Denote by $y_{a \infty}(s)$ the steady state level of production of agricultural goods, where

$$
y_{a \infty}(s)=[\alpha /(\rho+\delta)]^{\frac{\alpha}{1-\alpha}}\left[1-\beta L_{\infty}(s)\right]^{1 /(1-\alpha)} L_{\infty}(s) .
$$

We have $y_{a \infty}^{\prime}(s)=L_{\infty}^{\prime}(s) d y_{a \infty}(s) / d L$, where

$$
\frac{d y_{a \infty}(s)}{d L}=\left[\frac{\alpha(1-\beta L)}{\rho+\delta}\right]^{\frac{\alpha}{1-\alpha}}\left[1-\frac{2-\alpha}{1-\alpha} \beta L\right] .
$$

Given $\frac{1-\alpha}{2-\alpha}<\frac{\xi}{1+\xi}<\beta$ using H1, $y_{a \infty}(s)$ is increasing in $L$ if $L \leq \frac{1-\alpha}{\beta(2-\alpha)}$, whereas it is decreasing in $L$ if $\frac{1-\alpha}{\beta(2-\alpha)} \leq L$. Using lemma 2 that states $L_{\infty}^{\prime}(s)<0$, the function $y_{a \infty}(s)$ is concave in $s$ and reaches a maximum for the rate of transfer $s_{A}$, given by $s_{A}=\frac{(1-\alpha) \rho \nu}{2-\alpha}\left[\frac{\alpha}{(2-\alpha)(\rho+\delta)}\right]^{\frac{\alpha}{1-\alpha}}$. Comparing $s_{A}$ with $\bar{s}$ (determined by $\left.L_{\infty}(\bar{s})=L_{0}\right)$ gives

$$
\frac{s_{A}}{\bar{s}}=\frac{(1-\alpha) \rho \nu}{\xi-\beta L_{0}(1+\xi)}\left[(2-\alpha)\left(1-\beta L_{0}\right)^{\alpha}\right]^{-1 /(1-\alpha)}<1 .
$$


Using proposition 1 implies $K_{a \infty}^{\prime}(s)=L_{\infty}^{\prime}(s) d K_{a \infty}(s) / d L$, where

$$
\frac{d K_{a \infty}(s)}{d L}=\left[\frac{\alpha(1-\beta L)}{\rho+\delta}\right]^{\frac{1}{1-\alpha}}\left[1-\frac{\beta L}{(1-\alpha)(1-\beta L)}\right]
$$

which is equal to zero for $L=\frac{1-\alpha}{\beta(2-\alpha)}$. Hence, $K_{a \infty}(s)$ is also concave in $s$ and reaches a maximum for the rate of transfer $s_{A}$. The steady state agricultural revenue net of investment also finds a maximum for $s_{A}$ because

$$
y_{a \infty}^{\prime}(s)-\delta K_{a \infty}^{\prime}(s)=y_{a \infty}^{\prime}(s)[1-\alpha \delta /(\rho+\delta)],
$$

where the bracketed term is positive.

By definition (6), the steady state transfer is $S\left(1-L_{\infty}(s), 0\right)=\gamma-$ $\gamma L_{\infty}(s)+R d_{\text {bas }}$, which is an increasing function of $s$ given $s=\gamma+\rho R$ and $L_{\infty}^{\prime}(s)<0$. Using $(26)$ and keeping $\gamma$ constant implies that $(26)$ is a concave function of $s$ which finds a maximum for $s_{C}$ such that

$$
y_{a \infty}^{\prime}\left(s_{C}\right)=\frac{\rho+\delta}{\rho+(1-\alpha) \delta}\left[\gamma L_{\infty}^{\prime}\left(s_{C}\right)-d_{b a s} / \rho\right]<0
$$

Hence, $s_{A}<s_{C}$. Furthermore $s_{C}<\bar{s}$ iff $y_{a \infty}^{\prime}(\bar{s})[1-\alpha \delta /(\rho+\delta)]-\gamma L_{\infty}^{\prime}(\bar{s})+$ $d_{\text {bas }} / \rho<0$, which leads to

$d_{b a s}<\frac{\rho(1-\alpha)\left(1-\beta L_{0}\right) \bar{s}}{\beta\left[\left(1-\beta L_{0}\right)(1+\xi)-\alpha\right]\left[\xi-\beta L_{0}(1+\xi)\right]}\left[\left(1-\frac{\alpha \delta}{\rho+\delta}\right) \frac{\left[1-\frac{2-\alpha}{1-\alpha} \beta L_{0}\right] \bar{s}}{\xi-(1+\xi) \beta L_{0}}-\gamma\right]$,

where the bracketed term is positive if $\gamma$ is small compared to $\bar{s}$, which is the case assuming that $\gamma$ is fixed. Otherwise, we have $s_{C}=\bar{s}$. Furthermore, keeping $R$ constant implies that $(26)$ is a concave function of $s$ iff

$$
\left(1-\frac{\alpha \delta}{\rho+\delta}\right) \frac{\left[1-\frac{2-\alpha}{1-\alpha} \beta L_{0}\right] \bar{s}}{\xi-(1+\xi) \beta L_{0}}+s \frac{h^{\prime \prime}(L)}{\left(h^{\prime}(L)\right)^{2}}>2,
$$

which does not hold if $s=0$. A necessary and sufficient condition for concavity is $-y_{a \infty}^{\prime \prime}(s)[1-\alpha \delta /(\rho+\delta)]>d^{2} S\left(1-L_{\infty}(s), 0\right) / d s^{2}$. It requires that the change in $s$ is mostly driven by a change in $R$.

\section{Appendix F. Proof of Proposition 3}

33. can be expressed as $\tilde{h}(L)-(\gamma+r R) / n=0$, with $r=\rho+\delta$ and

$$
\tilde{h}(L)=[\alpha(1-\beta L) /(\rho+\delta)]^{\frac{\alpha}{1-\alpha}}\left[\xi_{a}-\beta L\left(1 / n+\xi_{a}\right)\right] .
$$


We have

$$
\tilde{h}^{\prime}(L)=-\frac{\beta}{1-\alpha}\left[\frac{\alpha(1-\beta L)}{\rho+\delta}\right]^{\frac{\alpha}{1-\alpha}}\left[\frac{1}{n}+\xi_{a}-\frac{\alpha}{n(1-\beta L)}\right]
$$

which is negative if and only if $L<\left(1-\alpha+n \xi_{a}\right) /\left[\beta\left(1+n \xi_{a}\right)\right]$. Using lemma 1 and $n \xi_{a}>\xi_{a}>\xi$ implies that $\tilde{h}^{\prime}(L)<0$ and that $(33)$ has a unique solution $\left(\tilde{L}_{\infty} \in\left[L_{0}, 1\right]\right)$ for a given scheme $(\gamma, R)$.

Comparing B.1 with F.1 implies that $\tilde{h}\left(L_{0}\right)>h\left(L_{0}\right)$ iff $\beta L_{0}[1-n+$ $n \nu(1-\alpha) \delta]<n \nu(1-\alpha) \delta$, which holds for $n>1 /[1-\nu(1-\alpha) \delta]$. Otherwise, if $n<1 /[1-\nu(1-\alpha) \delta]$, lemma 1 implies $L_{0}<\xi /[\beta(1+\xi)]$, thus the inequality also holds because $\xi /(1+\xi)<n \nu(1-\alpha) \delta /[1-n+n \nu(1-\alpha) \delta]$ for $n \geq 1$. $h(L)$ finds a minimum (zero) for $L_{\infty}=\xi /[\beta(1+\xi)]$, which is inferior to $\tilde{L}_{\infty}=\xi_{a} /\left[\beta\left(1 / n+\xi_{a}\right)\right]$ for which $\tilde{h}(L)$ finds a minimum (zero) because $n \xi_{a}>\xi$. To prove that the functions $h(L)$ and $\tilde{h}(L)$ do not cross, I proceed by contradiction. Hence, $h(L)=\tilde{h}(L)$ for $L^{*}=n \nu(1-\alpha) \delta /[\beta(1-n+n \nu(1-\alpha) \delta)]$, which is negative if $n>1 /[1-\nu(1-\alpha) \delta]$ and otherwise positive but leading to $h\left(L^{*}\right)<0$. Given a scheme $(\gamma, R), h(L)<\tilde{h}(L)$ for all $L \in\left[L_{0}, \tilde{L}_{\infty}\right]$. 